\title{
Performance Investigation of 40 GB/s DWDM over Free Space Optical Communication System Using RZ Modulation Format
}

\author{
Sooraj Parkash, ${ }^{1}$ Anurag Sharma, ${ }^{1}$ Harsukhpreet Singh, ${ }^{1}$ and Harjit Pal Singh ${ }^{2}$ \\ ${ }^{1}$ Department of Electronics and Communication Engineering, CT Institute of Technology \& Research, Jalandhar, Punjab 144008, India \\ ${ }^{2}$ Department of Electronics and Communication Engineering, CT Institute of Engineering Management \& Technology, \\ Jalandhar, Punjab 144008, India
}

Correspondence should be addressed to Sooraj Parkash; soorajparkash879@gmail.com

Received 4 September 2015; Revised 4 December 2015; Accepted 10 January 2016

Academic Editor: Giancarlo C. Righini

Copyright (C) 2016 Sooraj Parkash et al. This is an open access article distributed under the Creative Commons Attribution License, which permits unrestricted use, distribution, and reproduction in any medium, provided the original work is properly cited.

\begin{abstract}
We successfully demonstrate $40 \mathrm{~GB} / \mathrm{s} 8$ channels' Dense Wavelength Division Multiplexing (DWDM) over free space optical (FSO) communication system. Each channel is transmitting $5 \mathrm{~GB} / \mathrm{s}$ data rate in downstream separated by $0.8 \mathrm{~nm}(100 \mathrm{GHz}) \mathrm{channel}$ spacing with $1.8 \mathrm{GHz}$ filter bandwidth. DWDM over FSO communication system is very effective in providing high data rate transmission with very low bit error rate (BER). The maximum reach of designed system is $4000 \mathrm{~m}$ without any compensation scheme. The simulation work reports minimum BER for Return-to-Zero (RZ) modulation format at different channels 1,4 , and 8 are found to be $2.32 e^{-17}, 1.70 e^{-16}$, and $9.51 e^{-15}$ at $4000 \mathrm{~m}$ distance, respectively. Sharp increase in BER occurs if data rate and distance increase up to $10 \mathrm{~GB} / \mathrm{s}$ and $5000 \mathrm{~m}$.
\end{abstract}

\section{Introduction}

Free space optical (FSO) communication, also termed as optical wireless, is an optical communication technology that uses line of sight (LOS) communication system and tries to fulfill the need for high bandwidth over short distances [1]. Instead of transmitting the pulses of light through glass fiber, these light pulses are transmitted in a narrow beam through atmosphere [2]. FSO links are of low cost, simple, and easy to install [3]. Installation is easy because no license is required from FCC for using FSO [4]. Also, there is no time and money wastage in digging the street to lay fiber. But FSO is limited to shorter ranges due to atmospheric turbulences [5]. FSO channel affects the quality of signal due to atmospheric turbulence present, as FSO links are highly dependent on weather conditions. The fog, smoke, and rain and scintillations are the form of atmospheric turbulences which degrades the FSO link performance [6]. Many techniques have been proposed to improve the performance of FSO link like aperture averaging, diversity [7], or amplification of signal which can be done using optical amplifier [8].

Optical amplification of signal can be achieved by EDFA, Raman, or SOA. Most deployed optical amplifier is EDFA because the gain and bandwidth provided by EDFA are very high and due to high bandwidth it can be used for amplification of multiple wavelengths and therefore can be used with WDM network easily [9]. There is always a demand for broader bandwidth communication, which inspired the WDM technique in field of FSO communication [10]. WDM technique started a revolution in optical communication network due to the fact that capacity of system can be increased simply by increasing the number of channels and tightening the channel spacing without using more than one FSO link. So WDM approach can be applied in FSO systems to maximize bandwidth usage but in cheaper way [11, 12]. In examining FSO performance, it is important to take several FSO parameters into consideration. These parameters can be divided into two parts: internal parameters and external parameters. Internal parameters include optical power, wavelength, and bandwidth; in recent years WDM over FSO communication system has become very efficient communication system in wireless communication system due to its high data rate, security, and minimum bit error rate (BER) [11]. WDM is a next generation to deployment of FSO based access network which provides highest bandwidth [8]. 


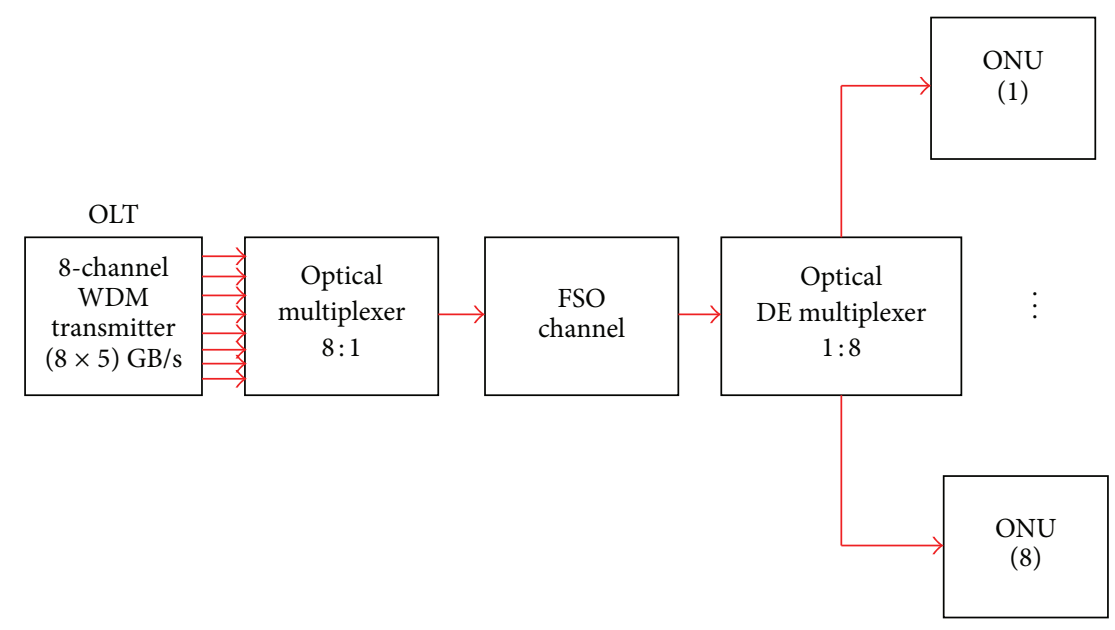

FIGURE 1: Simulation setup of 8-channel WDM over FSO communication system.

Coarse WDM can support 3-5 wavelengths if we increase the number of channels more than 5 it is called DWDM system. [13]. WDM is a natural approach to enhance the link capacity [14]. WDM provides point to point link connectivity from a single Optical Line Terminal (OLT) to each Optical Network Terminal (ONT) with uniquely assigned wavelengths to the users [7]. The application of WDM to the next-generation FSO access network has a focus on high bit rate, scalability, and flexibility [12]. In this paper we propose the simulative optical WDM transmitter and receiver with free space optical communication reported in Section 2. The simulation results have been discussed in Section 3. The conclusion of our simulative results is presented in Section 4.

\section{Experiment Setup}

The purpose of this research is to demonstrate a design free space optical communication link with a free space channel based on weak-turbulence approximation. Free space optical (FSO) communications, also known as wireless optical communications, are cost-effective and high bandwidth access technique and have compelling economic advantages, with the potential high data rate capacity, low cost, and particularly wide bandwidth on unregulated spectrum. In FSO communications, optical transceivers communicate directly through the air to form point to point line of sight links. The transmitter converts the electrical signal to an optical one and sends it through the atmosphere (free space). The receiver converts the optical signal back to an electrical signal. The quality of the transmission line is characterized by the realized bit-error rate (BER). Figure 1 shows the simulation setup of 8-channel WDM-FSO communication system. Figure 2 shows the OLT (Optical Line Terminal) components of WDM transmitter. OLT consists of PRBS generator, RZ Driver, and CW laser and $\mathrm{M}-\mathrm{Z}$ modulator. Optical power out of transmitter is $30 \mathrm{mw}$. A WDM transmitter transmits 8 channels having $0.8 \mathrm{~nm}$ channel spacing. Each channel is transmitting $5 \mathrm{~GB} / \mathrm{s}$ data rate downstream with input power $30 \mathrm{mw}$.

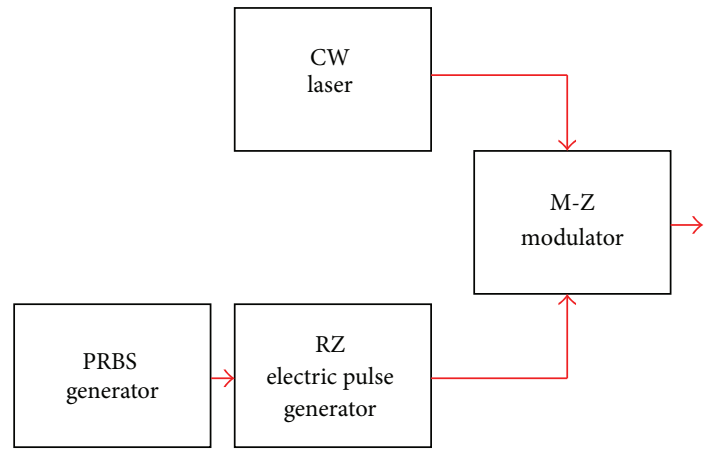

FIGURE 2: OLT components of WDM transmitter for single channel.

TABLE 1: Key parameters for simulation setup.

\begin{tabular}{lc}
\hline Parameters & Descriptions \\
\hline Number of channels & 8 \\
Channels spacing & $0.8 \mathrm{~nm}(100 \mathrm{GHz})$ \\
Range & $4 \mathrm{~km}$ \\
FSO transmitter aperture diameter & $5 \mathrm{~cm}$ \\
FSO receiver aperture diameter & $7.5 \mathrm{~cm}$ \\
Beam divergence & $0.25 \mathrm{mrad}$ \\
Attenuation & $3.5 \mathrm{~dB} / \mathrm{Km}$ \\
\hline
\end{tabular}

A Return-to-Zero (RZ) electric pulse generator used provides modulation format on digital data which is generated by PRBS (Pseudorandom Binary Sequence) generator. The whole data rate transmits in digital form 0 and 1 . The output of WDM transmitter is inserted into optical multiplexer. Optical multiplexer multiplexed all channels and inserted them into FSO channel. The FSO channel consists of optical attenuator and noise adder in $\mathrm{dB} / \mathrm{km}$. Table 1 shows key parameters for designed system. The model attenuator attenuates the input optical signal by the specified level of attenuation. The model noise adder may be used anywhere in the topology where a specified level of optical attenuation is desired. 
This model noise adder provides a mechanism for directly manipulating the ASE (Amplified Spontaneous Emission) noise of an optical spectrum. Additional noise can be added to the signal with various profiles. FSO link consists of transmitter FSO channel and receiver. To observe power at receiver and calculating the link margin, one can determine factors that affect quality of the link. Link margin is ratio of received power PR and receiver threshold or sensitivity $(S)$ and is usually expressed in $\mathrm{dB}$ :

$$
\text { Link Margin }=\frac{10 \log \mathrm{PR}}{S} .
$$

For signal to be recovered at receiver side, its power must be higher than receiver sensitivity. Sensitivity is usually given by manufacturer and it ranges from -20 to $40 \mathrm{dBm}$. Power at receiver can be expressed as

$$
P_{R}=P_{T} * e^{-\alpha L} * \frac{A_{R X}}{(\theta L)^{2}},
$$

where $P_{R}$ and $P_{T}$ are power at the receiver and transmitter, respectively, $A_{R X}$ is receiver aperture area, $\theta$ is divergence angle, $\alpha$ is atmospheric attenuation, and $L$ is distance between transmitter and receiver. As shown in (2), power at the receiver is directly proportional to the transmit power and receiver aperture area, but inversely proportional to the link range and divergence angle. Exponential part of the equation is related to atmospheric attenuation and it has the strongest influence on the link quality. The received power can be increased by increasing the transmitter power and the receiver area or by reducing the beam divergence of the transmitter beam. In our simulation work we investigated that as divergence angle is decreased the performance is improved considerably and the reliability of the link increases. Most current FSO systems use in transmitters either LED or diode or semiconductor lasers (e.g., CW) lasing at $800-850 \mathrm{~nm}$ or $1500-1550 \mathrm{~nm}$ wavelength. FSO link has a 4000 -meter range with beam divergence angle of $0.25 \mathrm{mrad}$. The FSO $T x$ and $R x$ diameters $5 \mathrm{~cm}$ and $7.5 \mathrm{~cm}$ are used in system. The environmental additional attenuation is specified by its mean value of $3.5 \mathrm{~dB} / \mathrm{km}$. Now the output of FSO channel is inserted into optical DE-MUX. The optical demultiplexer separates each channel with $(0.8 \mathrm{~nm}) 100 \mathrm{GHz}$ channels spacing as it transmitted from WDM transmitter with the help of triangular optical filter and was received by individual ONU (Optical Network Unit) at receiving side. Figure 3 shows the ONU components at receiving side. On receiving side convert the optical data into electrical form. We use a high sensitivity receiver PIN detector which performs that function; the first one is to detect data in optical form and converted into the electrical signal. A low pass Bessel electric filter with $1.8 \mathrm{GHz}$ bandwidth is used to pass the limited low pass frequencies. We know that data is transmitting in digital domains 0 and 1 so noise in form of intersymbol interference may occur. So to measure the error we used an instrument called BER Tester.

\section{Results and Discussion}

WDM transmitter transmitted 8 channels with $0.8 \mathrm{~nm}$ $(100 \mathrm{GHz})$ channel spacing over FSO link. Figure 4 shows

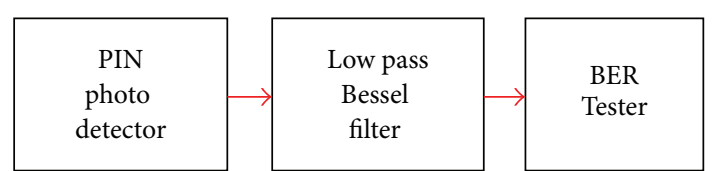

FIGURE 3: ONU components on receiving side.

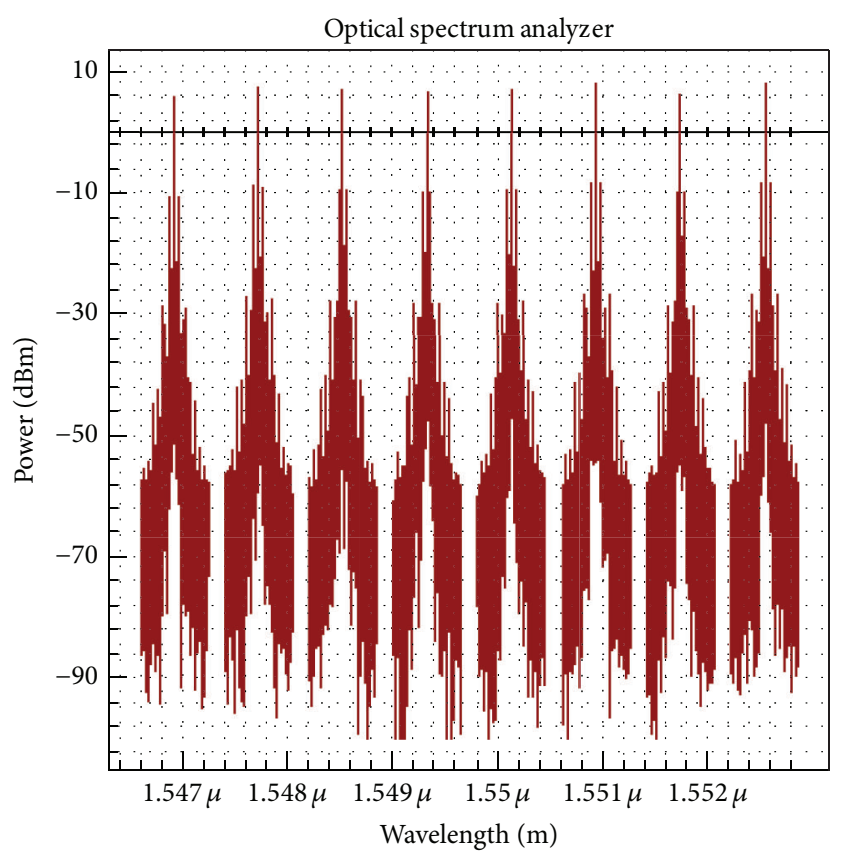

FIGURE 4: Output transmission wavelength spectrum of FSO channel.

TABLE 2: BER values for different channels for RZ modulation format at $4000 \mathrm{~m}$.

\begin{tabular}{lcc}
\hline Wavelengths $(\mathrm{nm})$ & BER & Q-factor $(\mathrm{dBm})$ \\
\hline$\lambda_{1}=1552.52$ & $2.32 e^{-17}$ & 8.48 \\
$\lambda_{4}=1550.11$ & $1.70 e^{-16}$ & 8.46 \\
$\lambda_{8}=1546.91$ & $9.51 e^{-15}$ & 7.45 \\
\hline
\end{tabular}

the transmission wavelength spectrum of FSO channel. By sampling method 3 channels $\lambda_{1}=1552.52, \lambda_{4}=1550.11$, and $\lambda_{8}=1546.91$ are selected for observation of WDM-FSO communication system.

Table 2 represents the BER for different channels at $4000 \mathrm{~m}$ distance. Figure 5 shows the BER versus distance at $4 \mathrm{~km}$ for RZ modulation format. It is clear that if distance increases BER also increases. For example, for channels 1, 4, and 8 the BER values are $1.55 e^{-92}, 9.64 e^{-90}$, and $1.911 e^{-85}$ at $1 \mathrm{~km}$ for RZ modulation format. For the same channels the BER values are obtained: $1.05 e^{-17}, 1.32 e^{-16}$, and $3.2 e^{-15}$ at $4 \mathrm{~km}$ for the same modulation format. So it has been observed that if FSO channel range increases BER also increases. Figure 6 shows $Q$-factor versus distance at $4 \mathrm{~km}$ for $\mathrm{RZ}$ modulation format. For channels 1, 4, and 8 the $Q$-values are 21, 20, and 21.3 at $4 \mathrm{~km}$ for RZ modulation format. For the same channels the $Q$-value are 8.48, 8.46, and 7.45 at $4 \mathrm{~km}$ for 


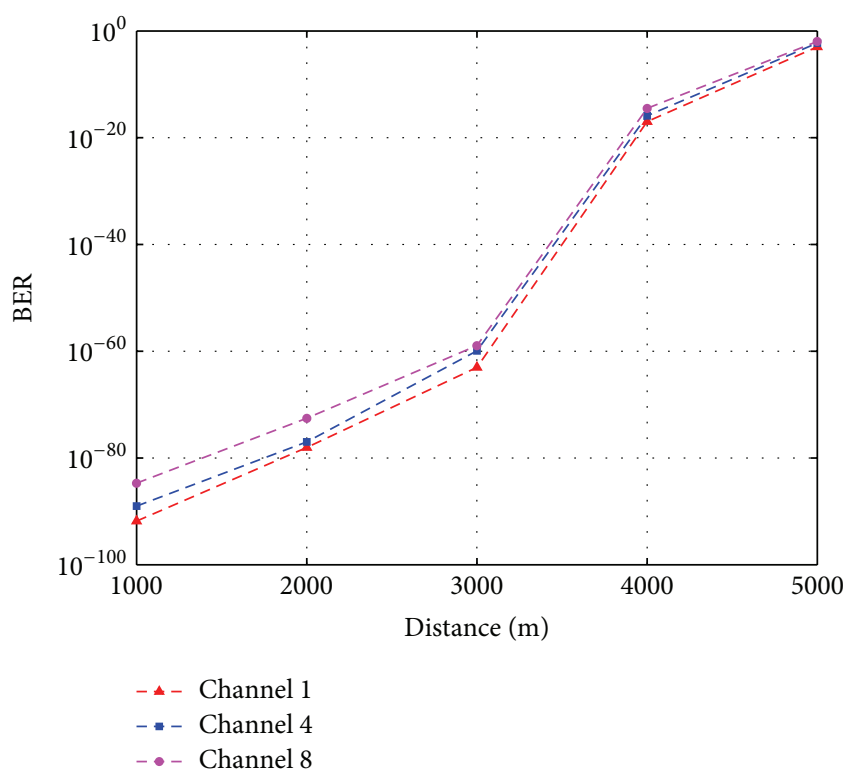

FIGURE 5: BER versus distance for RZ modulation format.

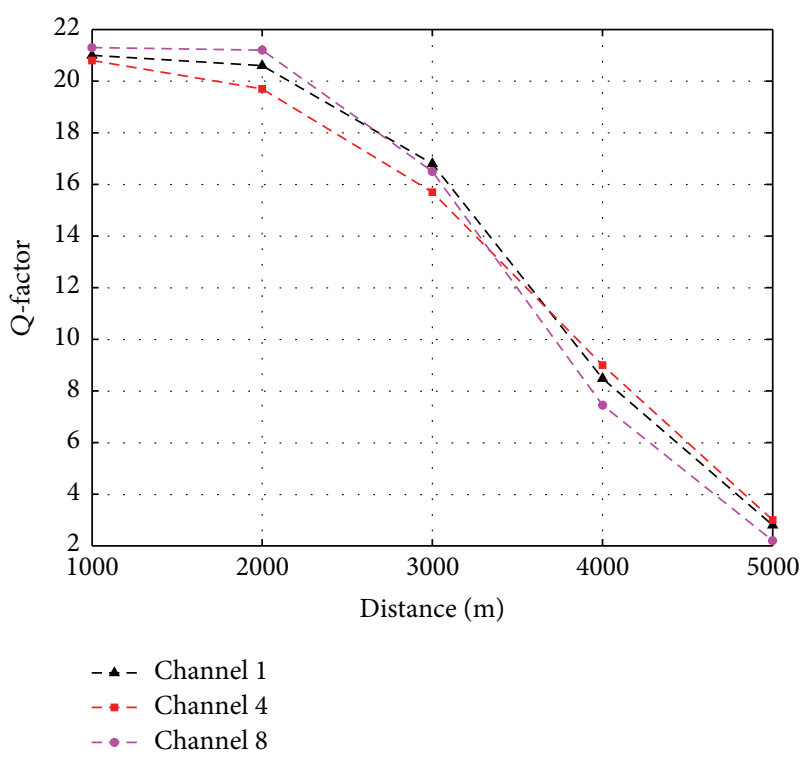

Figure 6: Q-factor versus distance for RZ modulation format.

the same modulation format. So it has been observed that distance also has effect on quality of received signal. If distance increases quality of received signal decreases. Figure $7 \mathrm{com}-$ pares system BER at various data rates at $4 \mathrm{~km}$. For channel 8 the values of BER are $1.39 e^{-72}, 3.97 e^{-42}, 3 e^{-15}$, and $1.23 e^{-2}$ for $1.25 \mathrm{~GB} / \mathrm{s}, 2.5 \mathrm{~GB} / \mathrm{s}, 5 \mathrm{~GB} / \mathrm{s}$, and $10 \mathrm{~GB} / \mathrm{s}$ for $\mathrm{RZ}$ modulation format at $4 \mathrm{~km}$, respectively. So it has been observed that when data rate per channel is increasing BER is also increasing. So there is tradeoff between data rate, distance, and BER.

Figure 8 shows BER versus signal power at $4 \mathrm{~km}$ for RZ modulation format. For channels 1,4 , and 8 the BER values are obtained as $1.04 e^{-3}, 1.32 e^{-3}$, and $7.04 e^{-2}$ for $10 \mathrm{~mA}$ at $4 \mathrm{~km}$. For the same channels the BER values are obtained as $2.56 e^{-39}, 3.57 e^{-37}$, and $2.49 e^{-34}$ for $60 \mathrm{~mA}$ at $4 \mathrm{~km}$. So it has

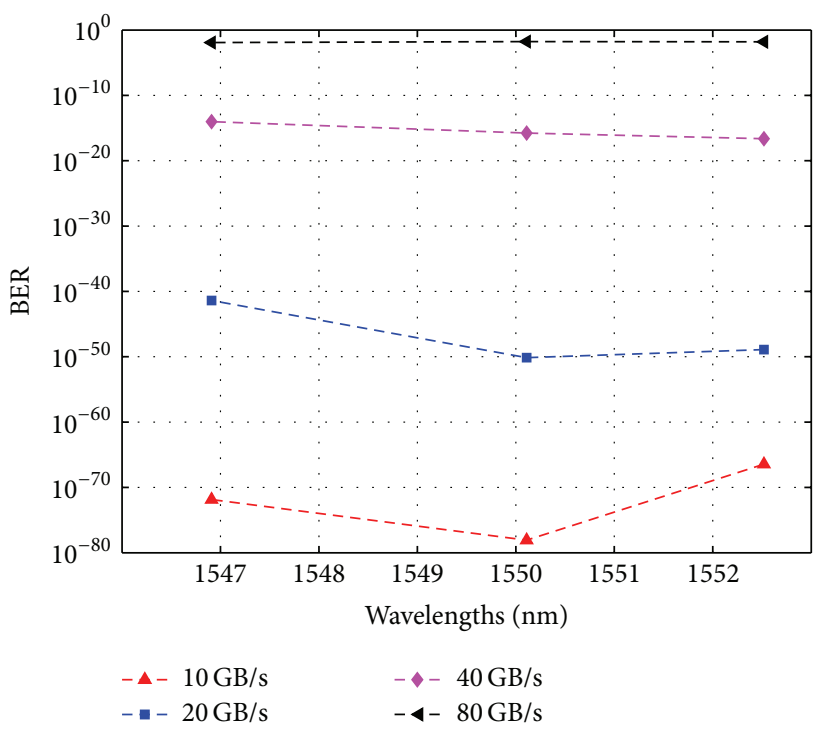

Figure 7: Comparison of system BER at different data rates.

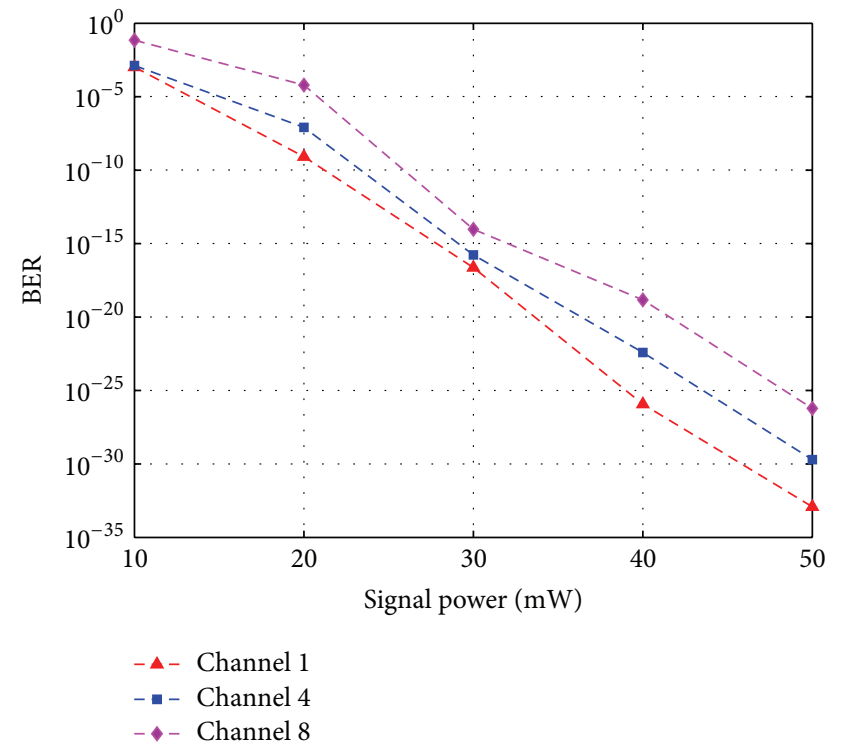

FIGURE 8: BER versus signal power for RZ modulation format at $4 \mathrm{~km}$.

been observed that if we increased signal power from WDM transmitter side BER is decreased. Figure 9 shows $Q$-factor versus signal power at $4 \mathrm{~km}$ for RZ modulation format. For channels 1, 4, and 8 the $Q$-values are found to be 3, 2.5, and 2 for $10 \mathrm{~mA}$ signal power at $4 \mathrm{~km}$. For the same channels the Q-values are found to be 13.1, 12.6, and 12.2 for $60 \mathrm{~mA}$ signal power at $4 \mathrm{~km}$. So it has been observed that signal power also affects quality of received signal. If we increased signal power quality of received signal strength is also increased.

Figure 10 compares system BER at different values of attenuation added in FSO channel. For channels 1, 4, and 8 values of BER are found to be $2.28 e^{-92}, 7.37 e^{-85}$, and $3.43 e^{-96}$ for $1 \mathrm{~dB} / \mathrm{km}$ attenuation added at $4 \mathrm{~km}$. For the same channels the values of BER are found to be $1.18 e^{-29}$, 


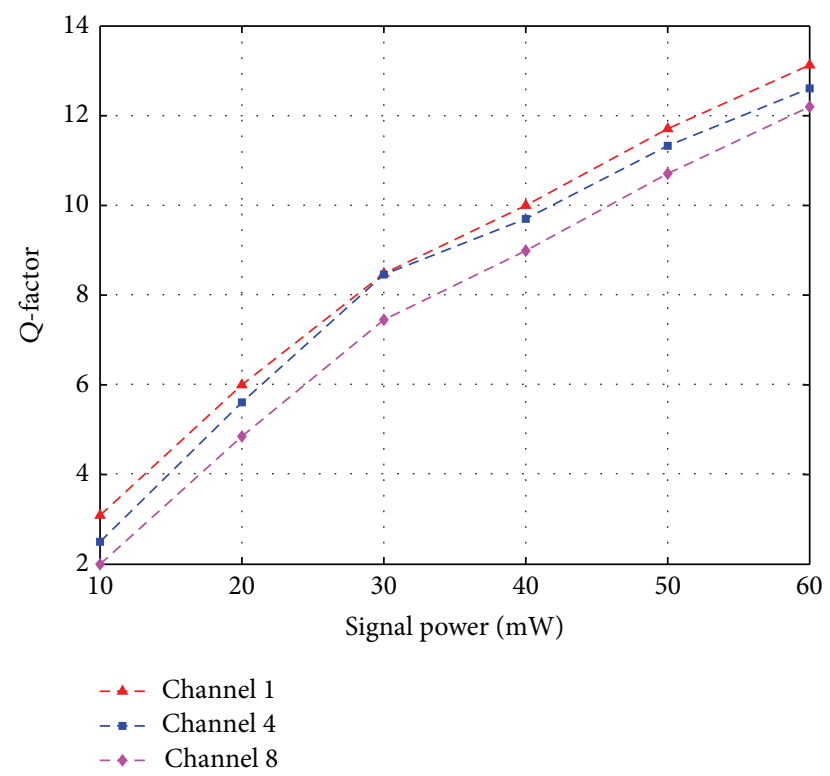

Figure 9: Q-factor versus signal power for RZ modulation format at $4 \mathrm{~km}$.

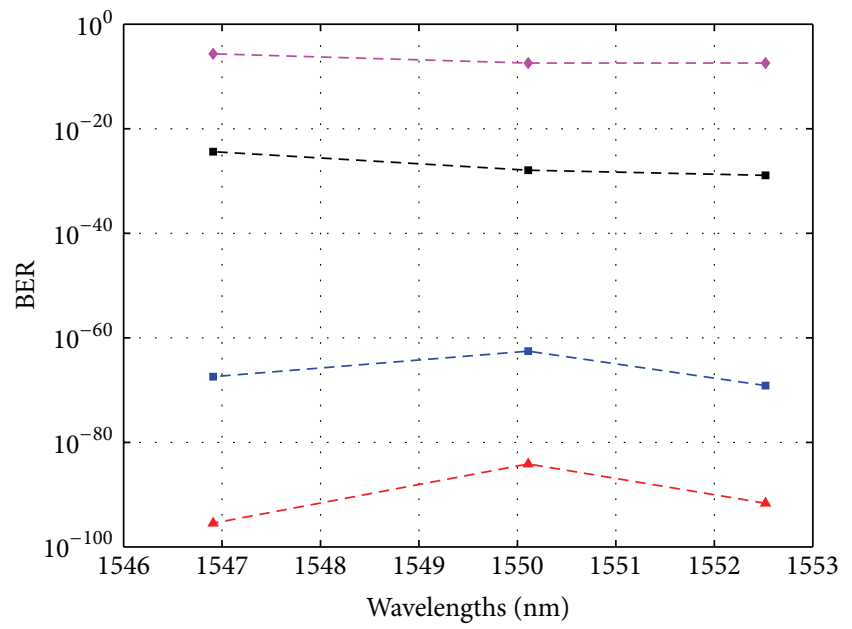

- - Attenuation added: $1 \mathrm{~dB} / \mathrm{km} \quad--$ Attenuation added: $3 \mathrm{~dB} / \mathrm{km}$ - - Attenuation added: $2 \mathrm{~dB} / \mathrm{km}$ - - Attenuation added: $4 \mathrm{~dB} / \mathrm{km}$

FIgURE 10: Comparison of system BER at different values of attenuation.

$1.15 e^{-28}$, and $4.07 e^{-25}$ and $3.62 e^{-8}, 3.67 e^{-8}$, and $2.07 e^{-6}$ for $3 \mathrm{~dB} / \mathrm{km}$ and $4 \mathrm{~dB} / \mathrm{km}$ at $4 \mathrm{~km}$. So it has been observed that if attenuation increases the loss of energy of received signal is more which results in sharp increase in BER. Figure 11 compares $Q$-factor at different values of attenuation added in FSO channel. For channels 1,4 , and 8 the $Q$-values are $20.3,19.48$, and 20.77 for $1 \mathrm{~dB} / \mathrm{km}$ attenuation at $4 \mathrm{~km}$. For the same channels the $Q$-values are 11.24, 11, and 10 and 5.38, 5.38, and 4.6 for $3 \mathrm{~dB} / \mathrm{km}$ and $4 \mathrm{~dB} / \mathrm{km}$ at $4 \mathrm{~km}$. Attenuation added in FSO channel also affects quality of received signal. More attenuation means more loss of energy of the received signal. Figure 12 shows comparison of system BER at different values of FSO transmitter beam divergence for $\mathrm{RZ}$ modulation

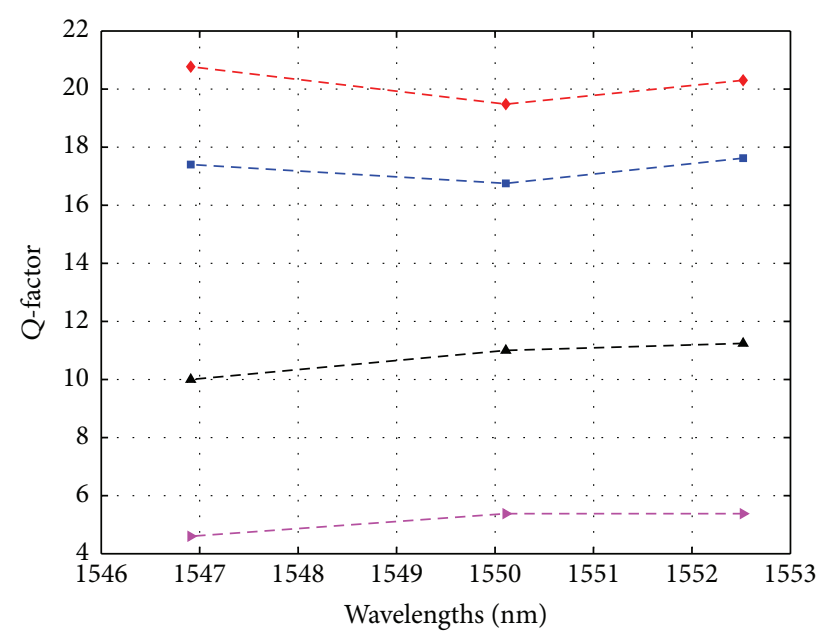

- - Attenuation added: $1 \mathrm{~dB} / \mathrm{km} \quad$ - $\_$- Attenuation added: $3 \mathrm{~dB} / \mathrm{km}$ - - Attenuation added: $2 \mathrm{~dB} / \mathrm{km} \quad \longrightarrow$ Attenuation added: $4 \mathrm{~dB} / \mathrm{km}$

FIGURE 11: Comparison of system Q-factor at different values of attenuation.

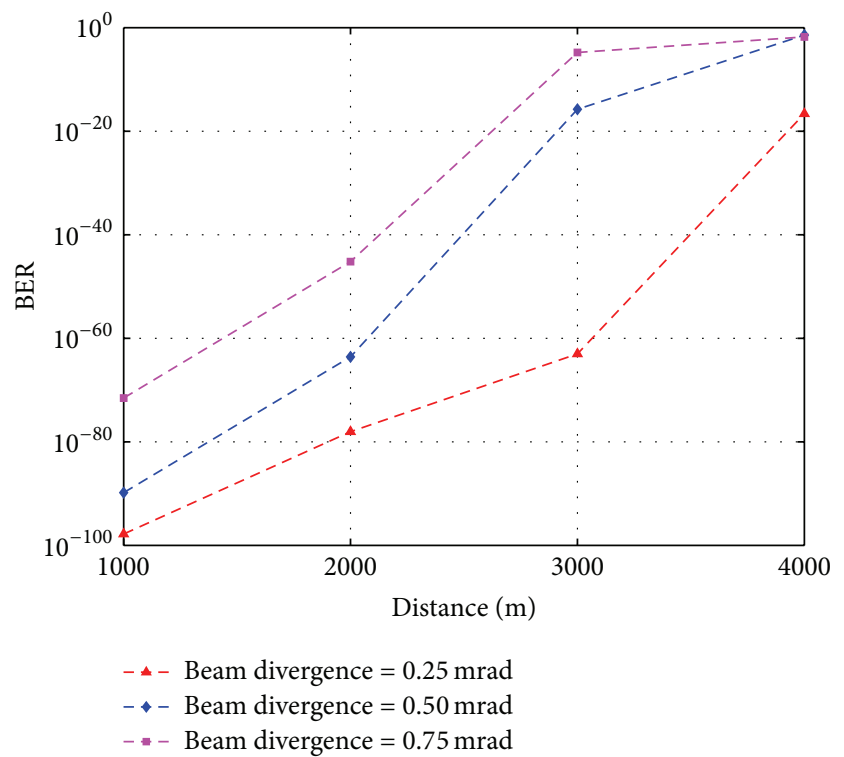

FIgURE 12: Comparison of system BER at different values of beam divergence for channel 1.

format at $4 \mathrm{~km}$. For channel 1 the value of BER is $1.55 e^{-98}$ and $2.32 e^{-17}$ at $1000 \mathrm{~m}$ and $4000 \mathrm{~m}$ for $0.25 \mathrm{mrad}$ beam divergence for RZ modulation formats. Similarly for the same channel the values of BER are $2.93 e^{-72}$ and $1.64 e^{-2}$ at $1000 \mathrm{~m}$ and $4000 \mathrm{~m}$ for $0.75 \mathrm{mrad}$ beam divergence for the same modulation format. So there is tradeoff between BER, distance, and transmitter beam divergence. If we increased FSO transmitter beam divergence BER is also increased.

Figure 13 compares $Q$-factor at different values of beam divergence. For channel 1 the $Q$-values are 21 and 8.48 at $1000 \mathrm{~m}$ and $4000 \mathrm{~m}$ for $0.25 \mathrm{mrad}$ beam divergence. Similarly for the same channel the $Q$-values are 16.5 and 2 at $1000 \mathrm{~m}$ and $4000 \mathrm{~m}$ for $0.75 \mathrm{mrad}$ beam divergence. It has been observed 


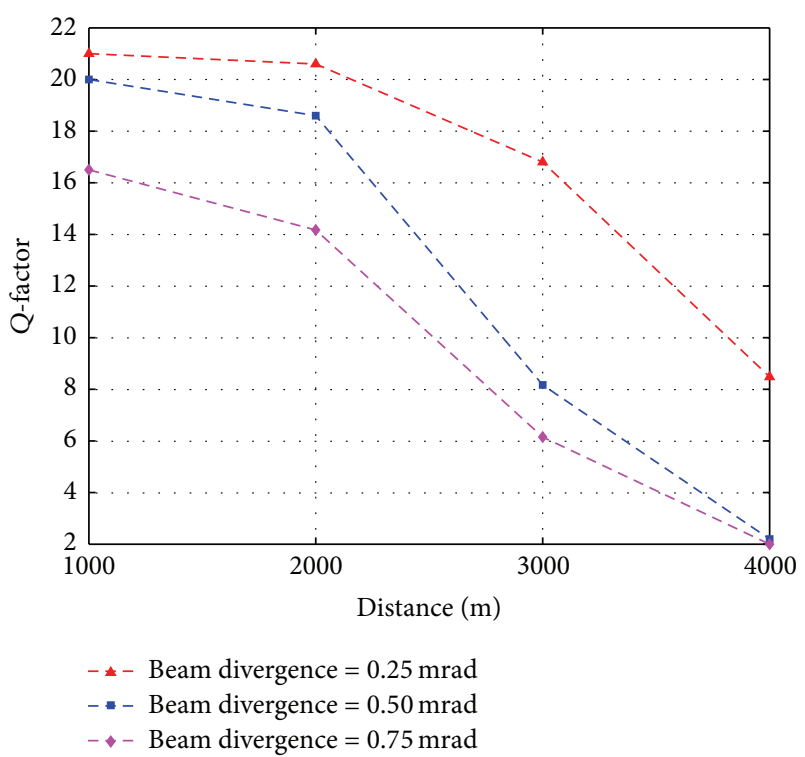

Figure 13: Comparison of system $Q$-factor at different values of beam divergence for channel 1 .

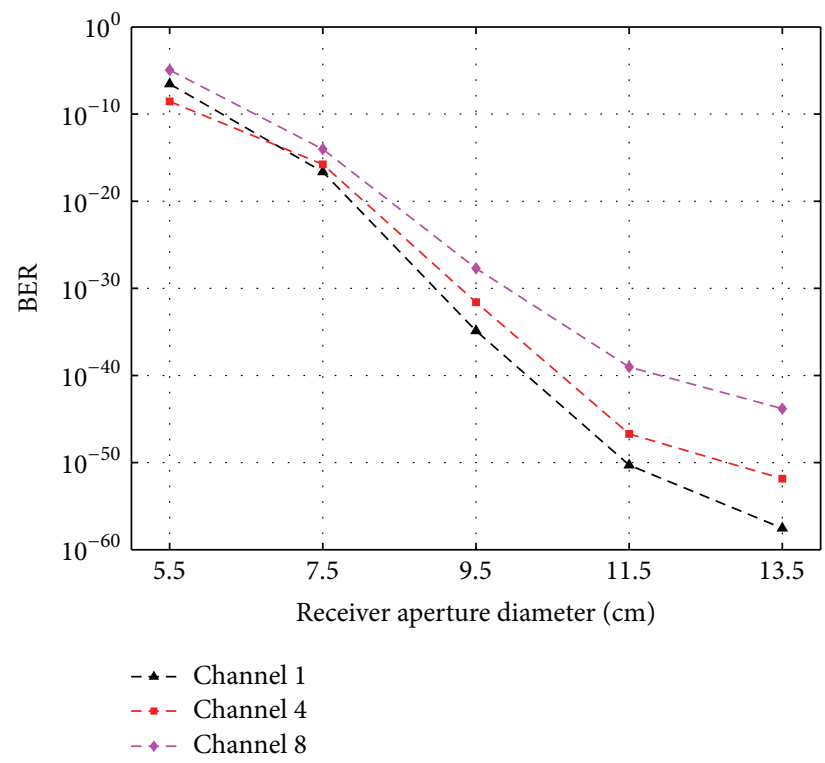

FIGURE 14: BER versus FSO aperture diameter for RZ modulation at $4 \mathrm{~km}$.

that if we increased FSO transmitter beam divergence quality of received signal is decreased. So there is tradeoff between BER, Q-factor, and beam divergence. Figure 14 shows BER versus receiver aperture diameter for $\mathrm{RZ}$ modulation format at $4 \mathrm{~km}$. For channels 1,4 , and 8 the values of BER are $2.89 e^{-7}, 2.86 e^{-9}$, and $1.14 e^{-5}$ for $5.5 \mathrm{~cm}$ aperture diameter at $4 \mathrm{~km}$ for RZ modulation format. For the same channels the values of BER are obtained as $2.95 e^{-58}, 1.43 e^{-52}$, and $1.55 e^{-44}$ for $13.5 \mathrm{~cm}$ aperture diameter at $4 \mathrm{~km}$ for RZ modulation format. It has been observed that if we increased FSO aperture diameter of receiver the BER is decreased.

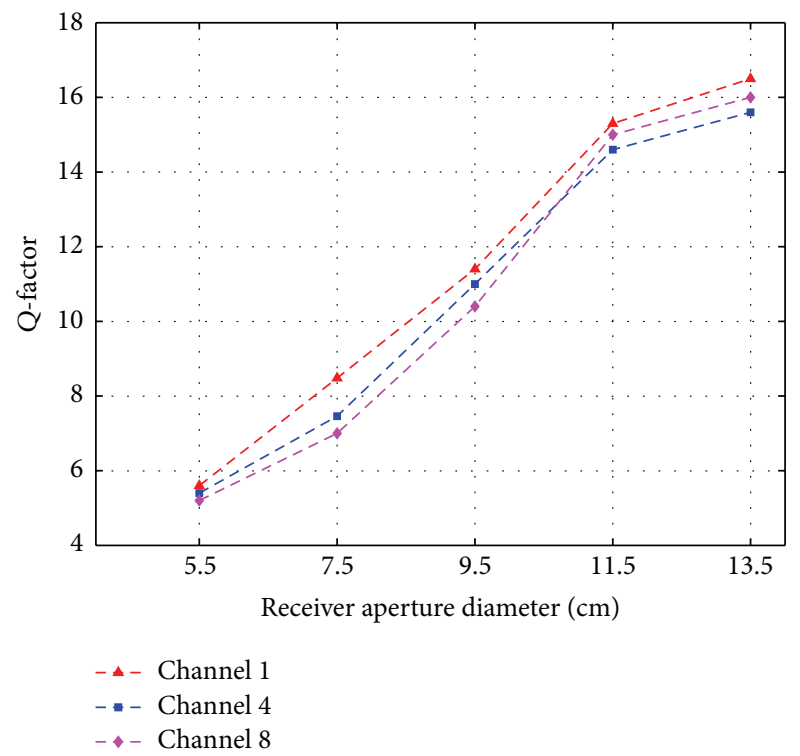

FIGURE 15: Q-factor versus FSO receiver aperture diameter for RZ modulation format at $4 \mathrm{~km}$.

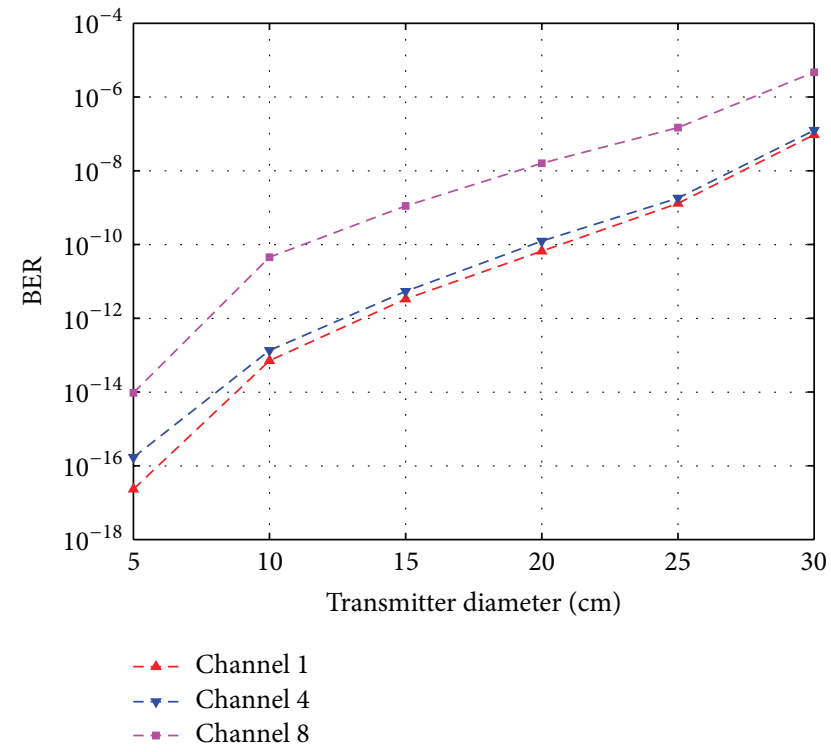

FIGURE 16: BER versus FSO transmitter diameter for RZ modulation at $4 \mathrm{~km}$.

Figure 15 shows the $Q$-factor versus FSO receiver aperture diameter at $4 \mathrm{~km}$ for RZ modulation format. For channels 1,4 , and 8 the $Q$-values are 7, 7.2, and 7 for $5.5 \mathrm{~cm}$ receiver aperture diameter at $4 \mathrm{~km}$ for RZ modulation format. For the same channels the $Q$-values are obtained as $16.5,15.6$, and 16 for $13.5 \mathrm{~cm}$ aperture diameter at $4 \mathrm{~km}$ for RZ modulation format. So it has been observed that receiver aperture diameter also improved quality of received signal. If we increased receiver aperture diameter quality factor also improved. Figure 16 shows BER versus FSO transmitter diameter for RZ modulation format at $4 \mathrm{~km}$. For channels 1,4 , and 8 the values of BER are $2.32 e^{-17}, 1.70 e^{-16}$, and $9.51 e^{-15}$ for 


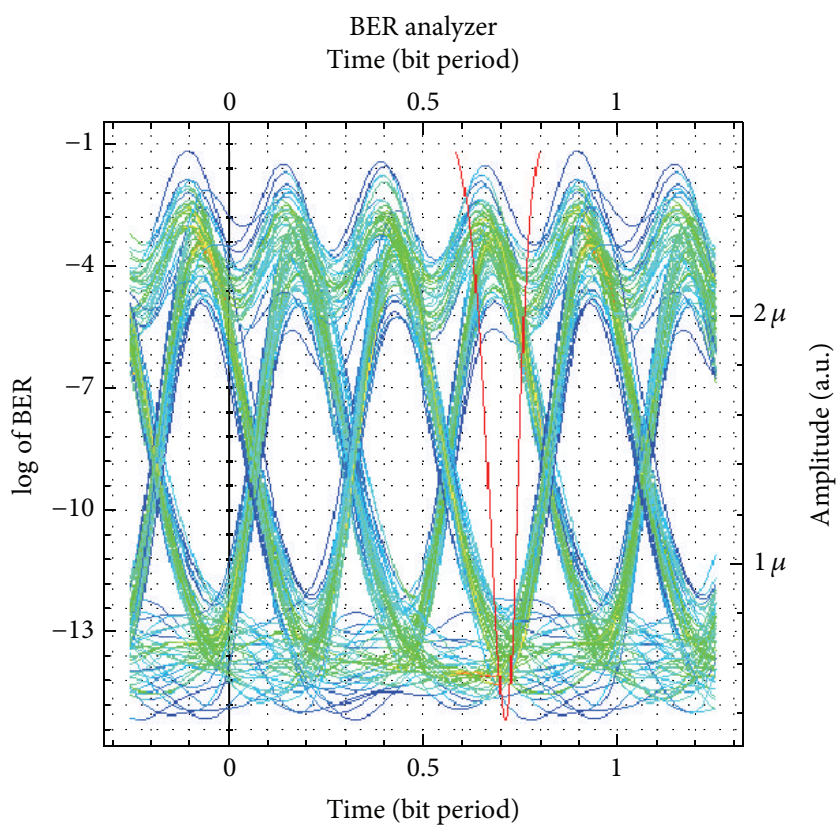

FIgURE 17: Eye diagram of data in case of channel 1 for RZ modulation at $4 \mathrm{~km}$.

$5 \mathrm{~cm}$ transmitter diameter for RZ modulation format at $4 \mathrm{~km}$. For the same channels the BER values are $9.48 e^{-8}, 1.25 e^{-7}$, and $4.69 e^{-6}$ for $30 \mathrm{~cm}$ transmitter diameter for the same specifications. So it has been observed that if FSO transmitter diameter increased BER is increased.

Figures 17, 18, and 19 depict the eye diagram for data in case of different channels for RZ modulation formats at $4 \mathrm{~km}$ distance. Eye diagram shows the width and height of the eye opening. Thus the width and height of the eye opening are large which means that reception of the signal is very much clear. The width of eye opening defines the time interval over which received signal can be sampled without interference and distortion. It has been observed that the RZ modulation format is much better for designed WDMFSO communication system because the opening of eye for RZ format is much better. More opening of eye means less intersymbol interference, dispersion, and distortion.

\section{Conclusion}

We successfully demonstrate $40 \mathrm{~GB} / \mathrm{s}$ WDM over FSO communication system at $4000 \mathrm{~m}$ length downstream. Performance investigation on this designed WDM over FSO was carried out using RZ modulation with different parameters such as signal power, FSO transmitter and receiver diameter, beam divergence, attenuation, and distance. It is concluded that RZ gives us excellent performance in WDM over FSO communication system; further FSO receiver and transmitter diameter range also increases with the increase in transmitter power. However, transmission range increases with the decreasing factor of attenuation and beam divergence in WDM over FSO communication system. It is also concluded that the performance of WDM over FSO communication

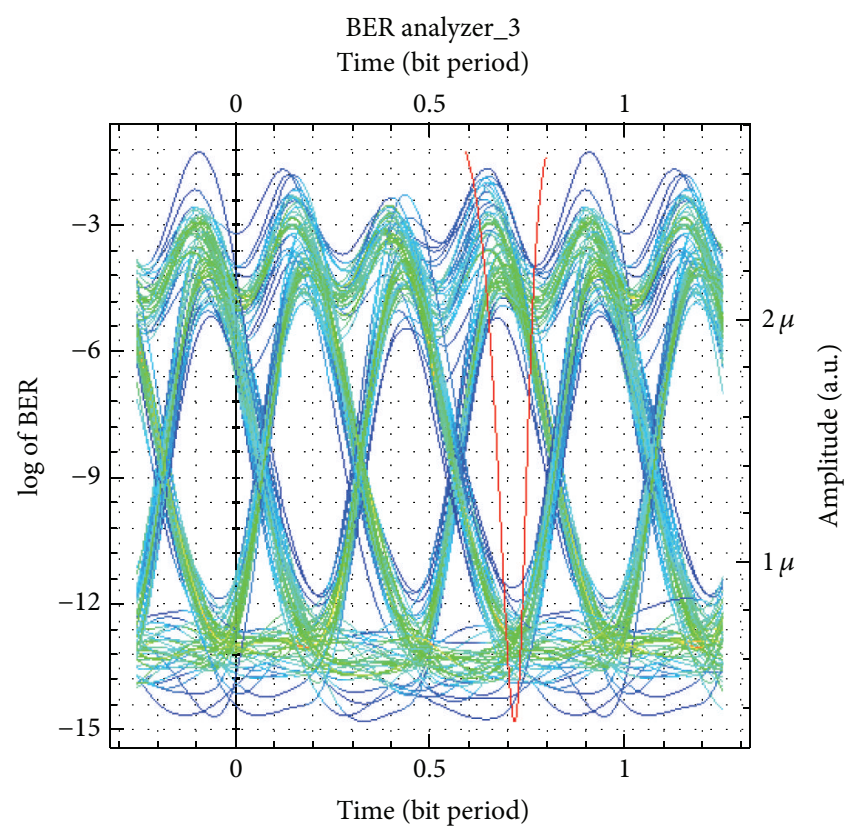

FIgURE 18: Eye diagram of data in case of channel 4 for RZ modulation at $4 \mathrm{~km}$.

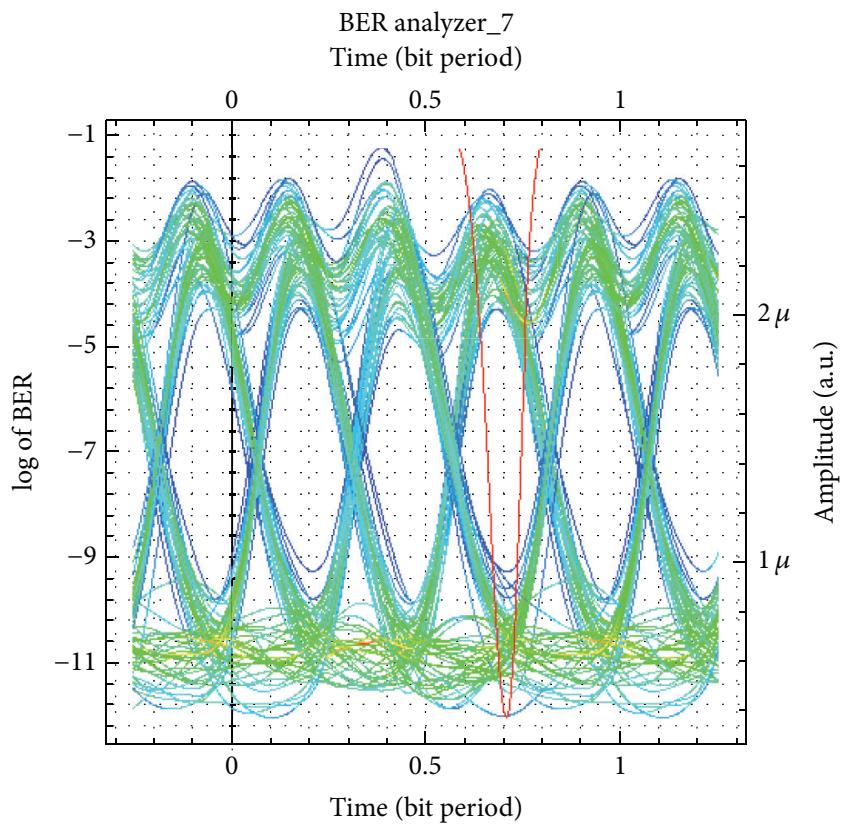

FIGURE 19: Eye diagram of data in case of channel 8 for RZ modulation at $4 \mathrm{~km}$.

system is degraded by increasing data rate up to $10 \mathrm{~GB} / \mathrm{s}$ on signal wavelength and range increases more than $4000 \mathrm{~m}$ which results in sharp increase in BER.

\section{Conflict of Interests}

The authors declare that there is no conflict of interests regarding the publication of this paper. 


\section{References}

[1] S. Parkash, P. K. Bhatia, D. Kumar, and H. Kaur, "Performance investigation of CRZ modulation format in GEPON fiber to the home (FTTH) network at 2.5G/bits for 200 ONU's," in Proceedings of the 2nd International Conference on Advances in Computing and Communication Engineering (ICACCE '15), vol. 1, pp. 360-365, IEEE, Dehradun, India, May 2015.

[2] E. Ciaramella, Y. Arimoto, G. Contestabile et al., "1.28 Terabit/s $(32 \times 40 \mathrm{Gbit} / \mathrm{s}) \mathrm{WDM}$ transmission over a double-pass free space optical link," in Proceedings of the Conference on Optical Fiber Communication (OFC '09), pp. 1-3, San Diego, Calif, USA, March 2009.

[3] N. Kumar and T. Singh, "2.50 Gbit/s optical CDMA over FSO communication system," Optik-International Journal for Light and Electron Optics, vol. 125, no. 16, pp. 4538-4542, 2014.

[4] S. Chaudhary, P. Bansal, and M. Lumb, "Effect of beam divergence on WDM-FSO transmission system," International Journal of Computer Applications, vol. 93, no. 1, pp. 28-32, 2014.

[5] J. Wang, J. Lv, G. Zhao, and G. Wang, "Free-space laser communication system with rapid acquisition based on astronomical telescopes," Optics Express, vol. 23, no. 16, pp. 41-50, 2015.

[6] H. M. Oubei, C. Li, K. Park, T. K. Ng, M. Alouini, and B. S. Ooi, "2.3 Gbit/s underwater wireless optical communications using directly modulated $520 \mathrm{~nm}$ laser diode," Optics Express, vol. 23, no. 16, pp. 20743-20748, 2015.

[7] V. Sharma and G. Kaur, "High speed, long reach OFDM-FSO transmission link incorporating OSSB and OTSB schemes," Optik-International Journal for Light and Electron Optics, vol. 124, no. 23, pp. 6111-6114, 2013.

[8] V. Sharma and Sushank, "High speed CO-OFDM-FSO transmission system," Optik, vol. 125, no. 6, pp. 1761-1763, 2014.

[9] S. Parkash, A. Sharma, M. Kumar, and H. Singh, "Performance enhancement of WDM-PON FTTH network by using decision feedback and feed forward equalizations," International Journal of Signal Processing, Image Processing and Pattern Recognition, vol. 8, no. 8, pp. 99-106, 2015.

[10] S. Parkash, D. Kumar, A. Sharma, and R. Malhotra, "Performance investigation of GE-PON fiber to the home network under varying data rates and users," in Proceedings of the International Multi-Track Conference (IMTC '14), vol. 1, pp. 156159, Jalandhar, India, June 2014.

[11] V. Sharma, M. Lumba, and G. Kaur, "Severe climate sway in coherent CDMA-OSSB-FSO transmission system," OptikInternational Journal for Light and Electron Optics, vol. 125, no. 19, pp. 5705-5707, 2014.

[12] L. Zhao, X. Chi, P. Li, and L. Guan, "A MPR optimization algorithm for FSO communication system with star topology," Optics Communications, vol. 356, pp. 147-154, 2015.

[13] S. Parkash, A. Sharma, and M. Kumar, "Performance investigation of CRZ modulation format in high speed 15X48GB/s WDM-PON," Australian Journal of Information Technology and Communication, vol. 2, no. 2, pp. 26-27, 2015.

[14] A. Sharma, M. Kumar, Ashima, and S. Parkash, "Dynamics of chirped RZ modulation format in GEPON fiber to the home (FTTH) network," International Journal of Electrical and Computer Engineering, vol. 2, no. 7, pp. 456-460, 2015. 


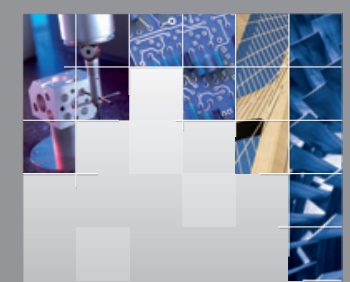

\section{Enfincering}
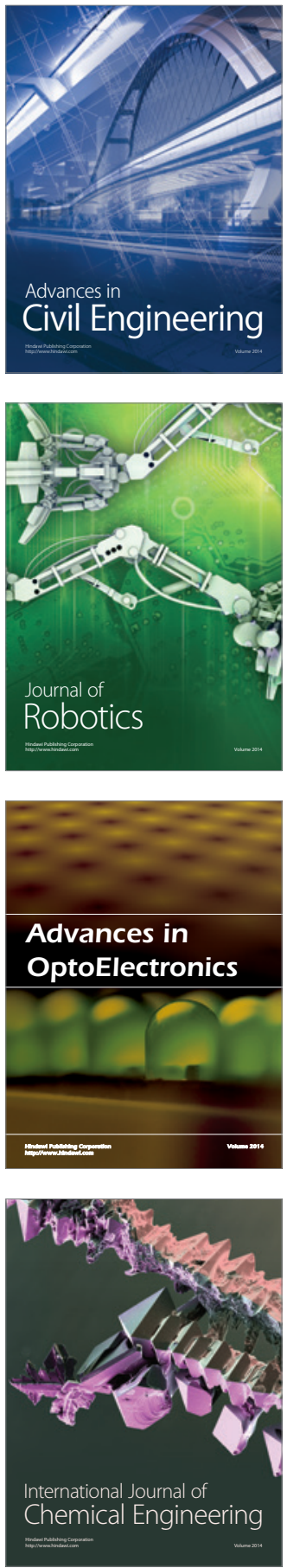

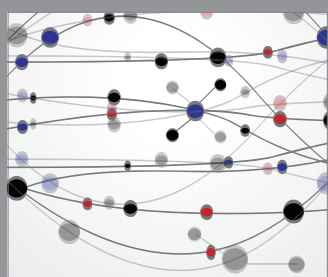

The Scientific World Journal

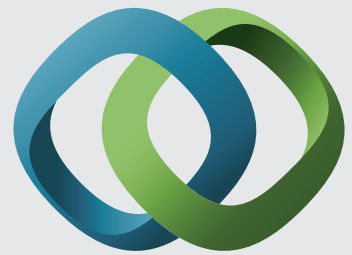

\section{Hindawi}

Submit your manuscripts at

http://www.hindawi.com
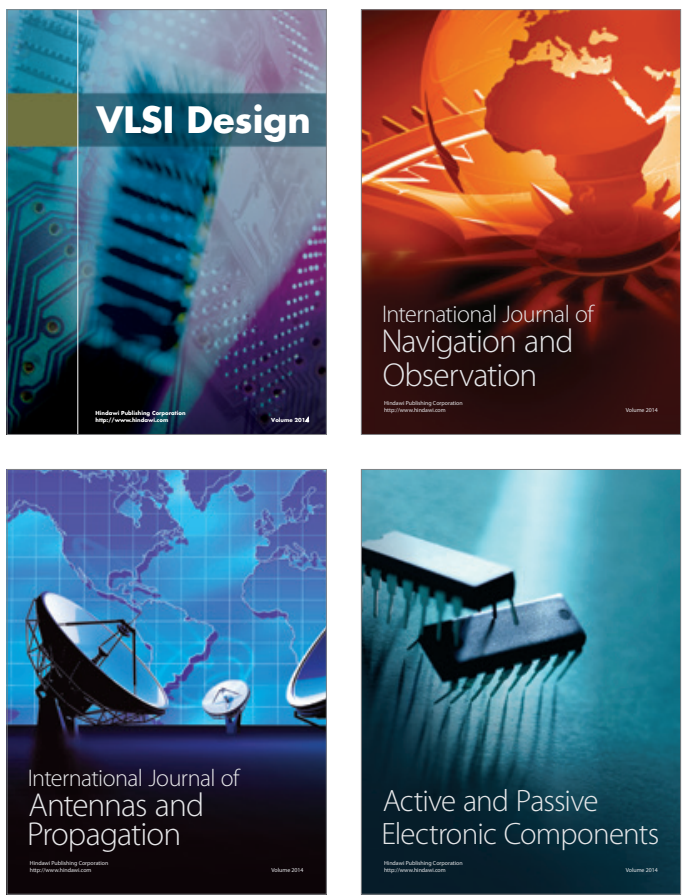
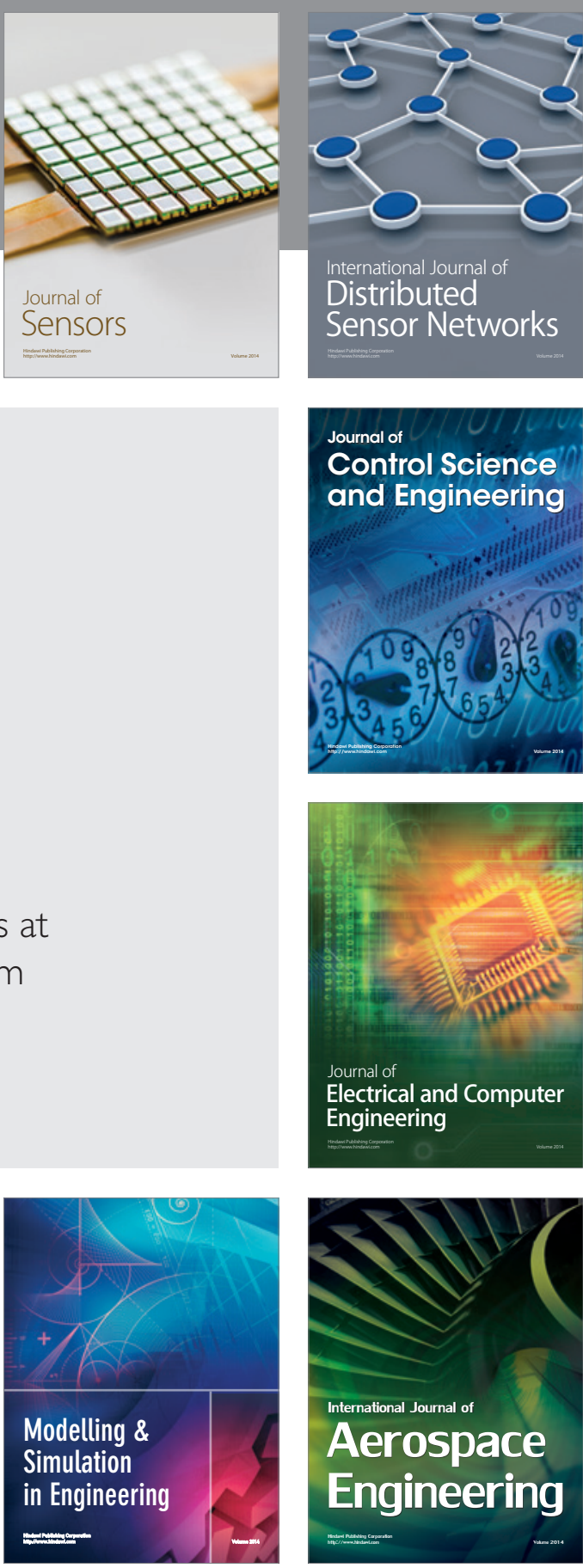

International Journal of

Distributed

Sensor Networks

Journal of

Control Science

and Engineering
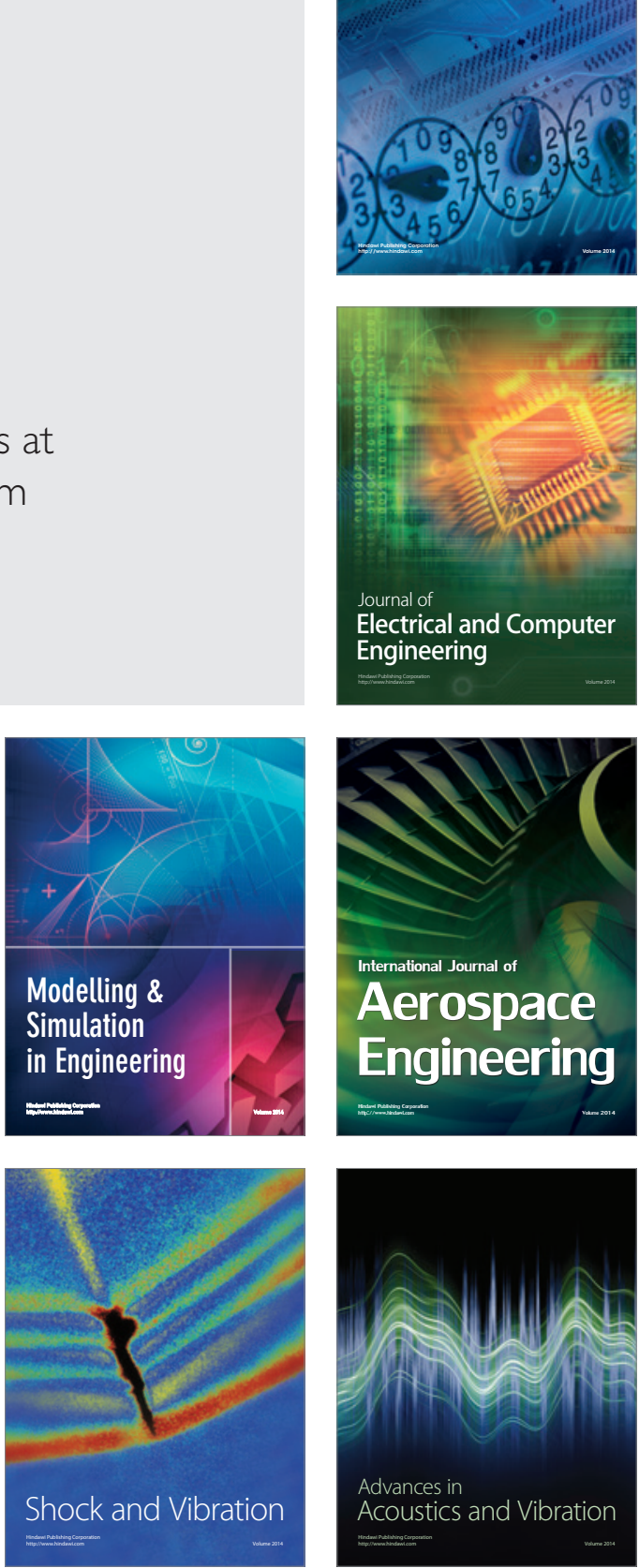